\title{
Aperture coupling rectangular slotted circular ring microstrip patch antenna
}

\author{
Abil Fathir Majid, Yulisdin Mukhlis \\ Universitas Gunadarma, Indonesia
}

\begin{tabular}{l}
\hline \hline Article Info \\
\hline Article history: \\
Received Oct 1, 2018 \\
Revised Dec 10, 2018 \\
Accepted May 3, 2019 \\
\hline
\end{tabular}

\section{Keywords:}

Aperture coupling

Circular ring

LTE

Microstrip patch antenna

Rectangular slot

\begin{abstract}
This paper designed circular ring microstrip patch antenna using aperture coupling feeding techniques with rectangular slots on the patch for LTE. The use of aperture coupling feeding techniques were expected to optimize antenna parameters performance. The addition of rectangular slots on the patch produced multi resonant frequencies than the original characteristics. The simulated optimized design generated $1.8 \mathrm{GHz}, 2.1 \mathrm{GHz}$, and $2.72 \mathrm{GHz}$ with Return Loss value $-22.3683 \mathrm{~dB},-18.8133 \mathrm{~dB},-24.3451 \mathrm{~dB}$ and VSWR value $1.1648,1.259,1.1291$. Meanwhile, the measurement results of fabricated antenna showed the frequency produced by the antenna was 1.8 $\mathrm{GHz}$ with value of Return Loss and VSWR $-18.257 \mathrm{~dB}$ and 1.278 in a reference value of VSWR $<2$ and Return Loss $<-10 \mathrm{~dB}$.
\end{abstract}

Copyright $\odot 2019$ Institute of Advanced Engineering and Science. All rights reserved.

Corresponding Author:

Abil Fathir Majid,

Universitas Gunadarma,

Margonda Raya 100, Depok 16424, Indonesia.

Email: abilfm@student.gunadarma.ac.id

\section{INTRODUCTION}

Microstrip antenna is one type of antenna whose development began in the 1970s and is still a kind of antenna that is being developed. Microstrip antenna technology for wireless applications is currently growing rapidly. This is because the microstrip has the characteristics of low profile, lightweight and easy to integrate with other devices [1-2]. The reason in the selection of this microstrip antenna in various applications is the material that is simple and inexpensive but capable of delivering quite good performance even for standard wireless communication network nowadays.

LTE is a standard wireless communication network based on GSM/EDGE and UMTS/HSDPA for high speed data access using mobile phones or other mobile devices. The development of LTE technology in Indonesia is expected to improve the technology that already exists. The application of LTE technology in Indonesia uses a frequency band of $800 \mathrm{MHz}, 900 \mathrm{MHz}, 1800 \mathrm{MHz}, 2100 \mathrm{MHz}$ and $2300 \mathrm{MHz}$ [3]. With the characteristics of microstrip antenna that are small, light and easy to fabricate, it is suitable to support LTE technology [4-6]. To support LTE performance, many techniques can improve the quality of its antenna performance, one of which is using aperture coupling technique [7, 8]. However, microstrip antenna has a narrow bandwidth characteristic [7]. In order to enhance bandwidth of the antenna and helping microstrip antenna resonates multiple frequency bands, one of the method is to provide slots on the patch of microstrip antenna [9-11].

Antenna designed in this paper will combine the above research and latest author's research [12] to develop the previous microstrip antenna design in the form of circular ring microstrip patch antenna with the addition of rectangular slots on its patch using aperture coupling technique, so the LTE operating frequency criteria that has been established by Regulation No. 27 by Ministry of Communication and Informatics of Indonesia in 2015 [3] can be fulfilled. Ansoft HFSS Ver. 15.0.2 is used to design the microstrip antenna. 
Through the software design guidelines, it will be obtained an antenna that is ready to fabricate to then measure the antenna parameters.

\section{RESEARCH METHOD}

To simplify the process of designing the antenna, should be determined the systematic measures in the form of a flowchart described in Figure 1. The patch that is used in this paper is circular ring showed in Figure 2 which is a development of circular patch that is known to be good for enhancing the bandwidth [13] and multi-resonating frequencies application [14], where the radius dimension of radiating element can be calculated by the [15].

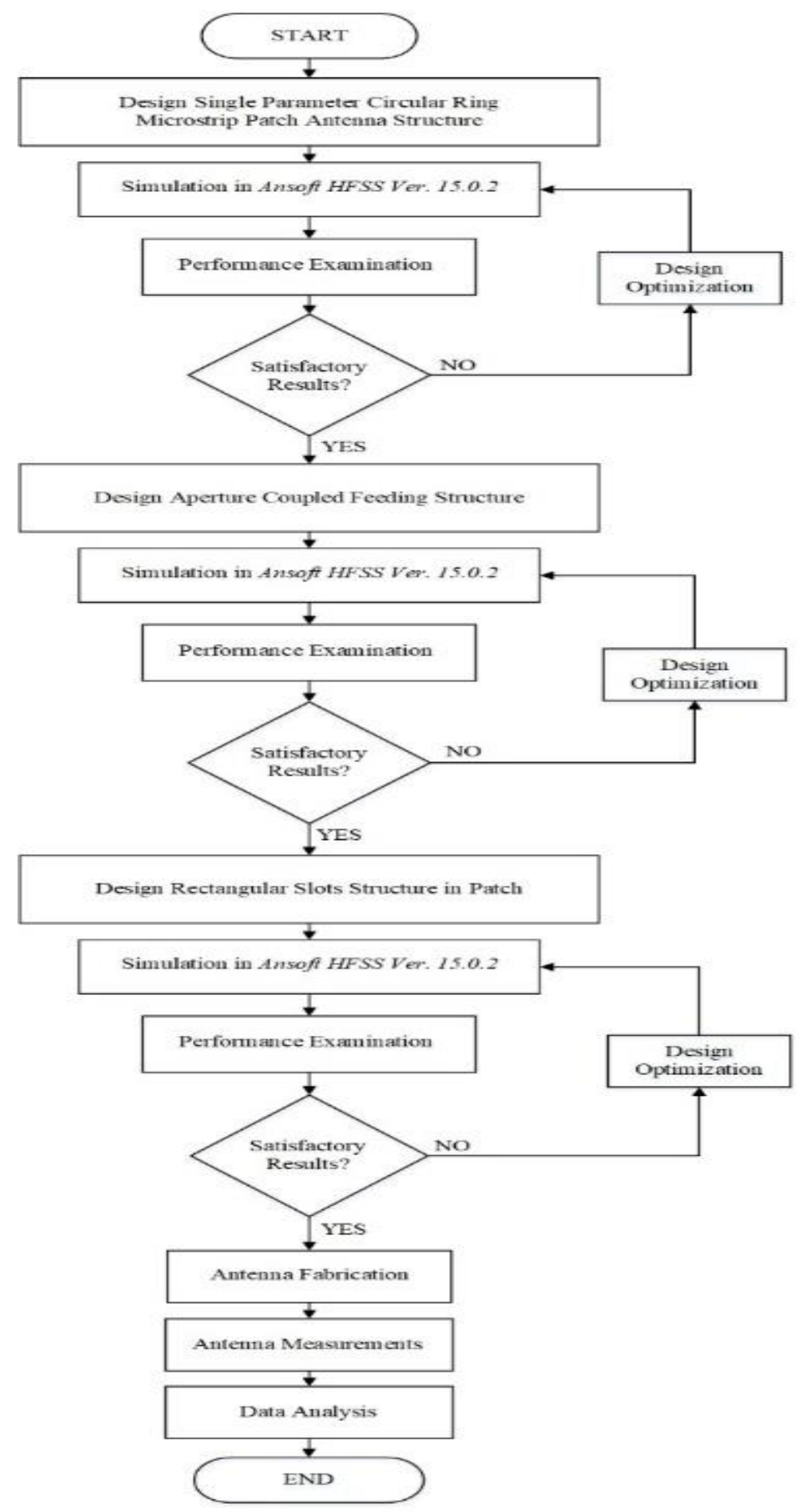

Figure 1. Flowchart of antenna design 


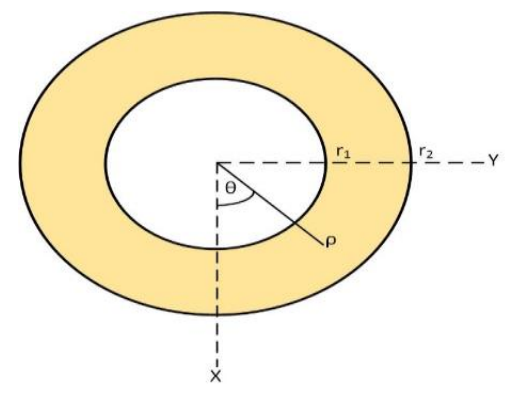

Figure 2. Geometric shape of circular ring radiating element

$$
f_{r}=\frac{c}{\pi r_{2}} \sqrt{\frac{1+\varepsilon_{r}}{2 \varepsilon_{r}}}
$$

$f_{r}=$ resonant frequency $(\mathrm{Hz})$

$\mathrm{r}_{2}=$ outer radius $(\mathrm{m})$

$\mathrm{c}=$ speed of light $\left(3 \times 10^{8} \mathrm{~m} / \mathrm{s}\right)$

$\varepsilon_{\mathrm{r}}=$ dielectric constant $(\mathrm{F} / \mathrm{m})$

by the [2]:

The minimum dimensions required by the ground plane of microstrip antenna can be searched

$$
\begin{aligned}
& L_{g}=6 h+2 r_{2} \\
& W_{g}=6 h+\frac{\pi}{2} r_{2}
\end{aligned}
$$

$\mathrm{L}_{\mathrm{g}}=$ minimum length of ground plane (m).

$\mathrm{W}_{\mathrm{g}}=$ minimum width of ground plane $(\mathrm{m})$.

$\mathrm{r}_{2}=$ outer radius of circular ring patch $(\mathrm{m})$.

$\mathrm{h}=$ substrate thickness $(\mathrm{m})$.

To bring an enhancement for the antenna, there will be using one of the popular method in modifying the coupling level of antenna by applying aperture coupled feeding technique. The aperture can be configured in variety of shapes with general configuration that is found as shown in Figure 3.

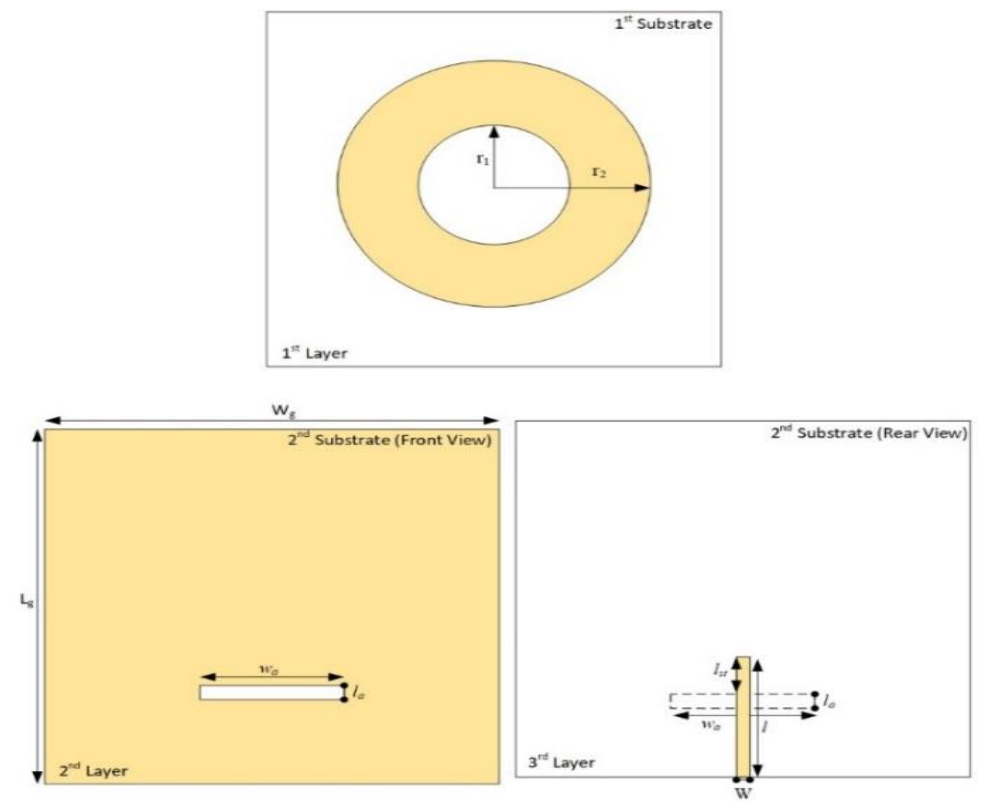

Figure 3. Geometric shape of aperture coupled circular ring microstrip patch antenna 
The critical concern of parameters in aperture coupled feeding technique is the size of its aperture. When referring to the configuration of aperture couple microstrip patch in Figure 3, the influence of width and length of aperture is not the same. The major advantages of aperture coupling feed technique is that it allows an independent optimization for both radiating patch and feed line of microstrip antenna [16, 17]. The bandwidth of linearly polarized antenna is widened by selection of substrates and combination of two resonances. One resonance is due to the patch and the other resonance results from the slot and its combination with the patch. Therefore, in order to obtain other resonance results, in this paper, we are going to design aperture couple microstrip patch antenna with best configuration of width and length of its aperture.

a) Position of The Coupling Aperture

For maximum coupling, the slot is placed below the patch center. Where the magnetic field is maximum. The feed line is positioned at right angle to the center of the slot [18].

b) Aperture Length

The aperture length affects the coupling level and the back radiation level. Based on the results in [18], the slot length should be chosen to be about.

$$
L_{a} \sim(0.1-0.2) \lambda_{0}
$$

c) Aperture Width

It is chosen as tenth of the aperture length [18].

$$
W_{a}=0.1 L_{a}
$$

d) Effective Stub Length real [18].

The stub length $L_{S}$ is adjusted until the input impedance at the design frequency becomes purely

$$
Z_{\text {in }}=R_{\text {in }}+j X_{\text {in }}=R+j X-j Z_{0} \cot \left(\frac{2 \pi L_{S_{\text {eff }}}}{\lambda_{f}}\right)
$$

Where $\mathrm{R}$ is the real part, and $\mathrm{X}$ is the imaginary part of the input impedance without stub.

The effective stub length can be defined by $\mathrm{Z}_{\text {in }}$ for $\mathrm{X}_{\text {in }}=0$ [18].

$$
L_{S_{e f f}}=\frac{\lambda_{0}}{2 \pi \sqrt{\varepsilon_{r_{e f f}}(f)}} \tan ^{-1}\left(\frac{X}{Z_{0}}\right)
$$

e) Stub Length

The stub length is given by [18].

$$
L_{S}=L_{S_{e f f}}-\Delta L_{S}
$$

Where the fringing stub length can be calculated by the following expressions [18].

$$
\begin{aligned}
& \Delta L_{S}=\frac{h_{f} g_{1} g_{2} g_{3} g_{5}}{g_{4}} \\
& g_{1}=0.434907 \frac{\left[\varepsilon_{r_{e f f}}(f)\right]^{0.81}+0.26}{\left[\varepsilon_{r_{e f f}}(f)\right]^{0.81}-0.189}\left(\frac{\left(\frac{W_{f}}{h_{f}}\right)^{0.8544}+0.236}{\left(\frac{W_{f}}{h_{f}}\right)^{0.8544}-0.87}\right) \\
& g_{2}=1+\frac{\left(\frac{W_{f}}{h_{f}}\right)^{0.371}}{2.358 \varepsilon_{r_{f}}+1}
\end{aligned}
$$




$$
\begin{aligned}
& g_{3}=1+\frac{0.5274 \tan ^{-1}\left[0.084\left(\frac{W_{f}}{h_{f}}\right)^{\frac{1.9413}{g_{2}}}\right]}{\left[\varepsilon_{r_{e f f}}(f)\right]^{0.9236}} \\
& g_{4}=1+0.0377 \tan ^{-1}\left[0.0670 .084\left(\frac{W_{f}}{h_{f}}\right)^{1.456}\right]\left\{6-5 e^{\left[0.036\left(1-\varepsilon_{r_{f}}\right)\right]}\right\} \\
& g_{5}=1-0.218 e^{\left[-7.5\left(\frac{W_{f}}{h_{f}}\right)\right]}
\end{aligned}
$$

Meanwhile, the development of slot that is used on the planar antenna with rectangular slots to have this following form as shown in Figure 4.

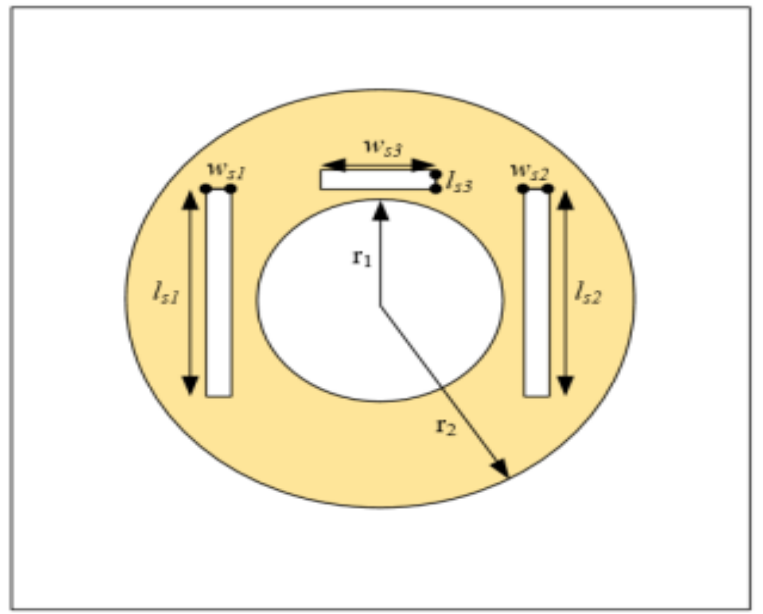

Figure 4. Geometric shape of rectangular slots on patch

The critical concern of parameters in adding slots on the patch is a resonant frequency. When referring to the configuration of rectangular slots above, the influence of width and length of the slot is not the same. With rectangular slot configuration in Figure 4, the slot length settings can produce an effect of the change in resonant frequency is not uniform. While, at the same time, setting width of the slot is able to take effect of frequency shifting that is no less powerful than the existing length adjustment slot. The effects that are not uniform will have impact on antenna performance due to frequency generated at each setting width and length of the slot is not the same. Therefore, in order to obtain an antenna design with multi resonant frequency, this paper are designing rectangular slots on the patch with best configuration of width and length that can produce another desired working frequency $[19,20]$.

\section{RESULTS AND DISCUSSION}

After going through several design optimization, each parameters that is used in last optimization is re-used in Ansoft HFSS simulator antenna for final simulation. Layout of the patch and aperture were still in the middle of substrate and lower middle of the ground plane. Dimension of substrate was equal to 130x130 $\mathrm{mm}$ with the change in size and dimensions of the aperture. To be clear, the design of desired antenna design can be seen in Figure 5.

The size specifications of designed antenna can be seen in Table 1. The form of antenna that has been fabricated can be seen in Figure 6. 

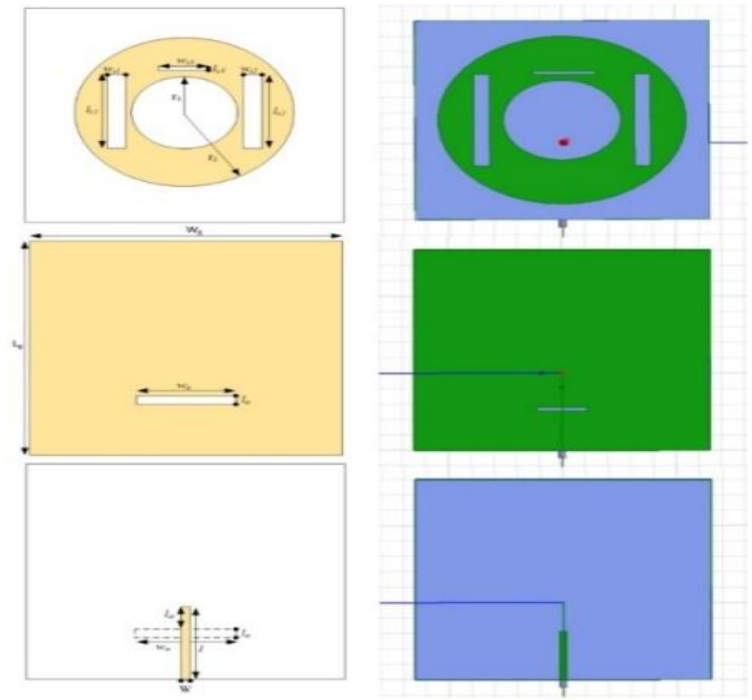

Figure 5. Design rectangular slotted circular ring microstrip patch antenna using aperture coupled antenna

Table 1. Final Design Specification of Rectangular Slotted Circular Ring Microstrip Patch Antenna using Aperture Coupled Antenna

\begin{tabular}{cc}
\hline Parameters & Size $(\mathrm{mm})$ \\
\hline Length of Substrate & 130 \\
Width of Substrate & 130 \\
Feed Line Width $(\mathrm{W})$ & 2.9921 \\
Feed Line Length $(l)$ & 27.5484 \\
Inner Radius $\left(\mathrm{r}_{1}\right)$ & 26.0848 \\
Outer Radius $\left(\mathrm{r}_{2}\right)$ & 52.1696 \\
Length of Ground Plane $\left(\mathrm{L}_{\mathrm{g}}\right)$ & 130 \\
Width of Ground Plane $\left(\mathrm{W}_{\mathrm{g}}\right)$ & 130 \\
Length of Aperture $\left(l_{a}\right)$ & 27 \\
Width of Aperture $\left(w_{a}\right)$ & 2.7 \\
Length of Stub $\left(l_{s t}\right)$ & 5.8595 \\
Length of Slot $1\left(l_{s l}\right)$ & 60 \\
Width of Slot 1 $\left(w_{s l}\right)$ & 7 \\
Length of Slot $2\left(l_{s 2}\right)$ & 60 \\
Width of Slot 2 $\left(w_{s 2}\right)$ & 7 \\
Length of Slot 3 $\left(l_{s 3}\right)$ & 2 \\
Width of Slot 3 $\left(w_{s 3}\right)$ & 27.8 \\
\hline
\end{tabular}

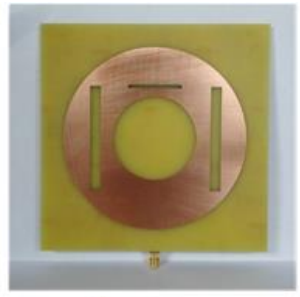

Front View

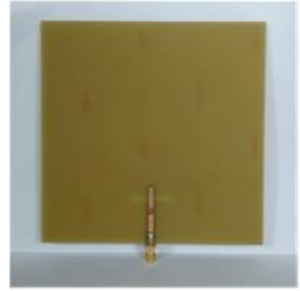

Rear View

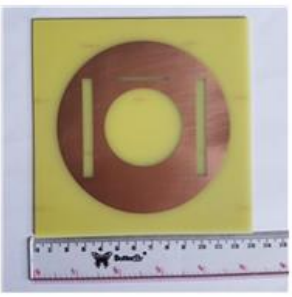

$1^{\text {st }}$ Layer View

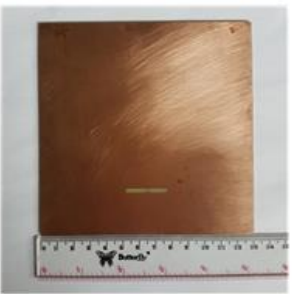

$2^{\text {nd }}$ Layer View

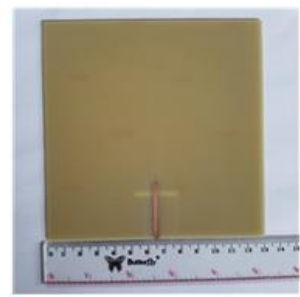

$3^{\text {rd }}$ Layer View

Figure 6. Form of fabricated antenna 


\subsection{Discussion of Single Port Antenna Parameters}

After going through various stages of design, single port parameters that are considered of preliminary measurements have met the criteria. If the value of measurement results compared with simulation results, it can be said that measurement result is worth slightly lower than the results of simulation. For more details of Return Loss comparison and VSWR result can be seen in Figure 7 and Table 2.
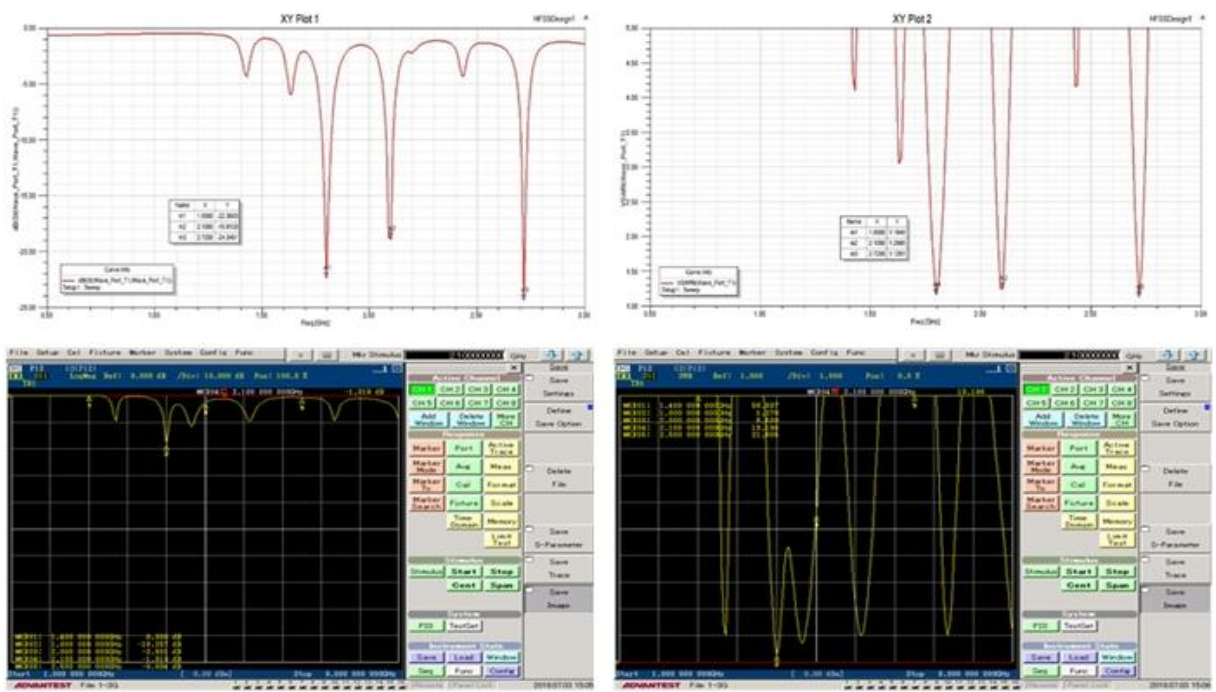

Figure 7. Comparisons of return loss and VSWR (top: simulation results, bottom: measurement results, left side: return loss results, right side: VSWR results)

Table 2. Comparisons of Return Loss and VSWR

\begin{tabular}{ccccccc}
\hline Resonant & \multicolumn{2}{c}{ Return Loss } & \multicolumn{2}{c}{ VSWR } & \multicolumn{2}{c}{ Bandwidth } \\
Frequency & Simulation & Measurement & Simulation & Measurement & Simulation & Measurement \\
\hline $1.8 \mathrm{GHz}$ & $-22.368 \mathrm{~dB}$ & $-18.257 \mathrm{~dB}$ & 1.1648 & 1.278 & $40 \mathrm{MHz}$ & $20 \mathrm{MHz}$ \\
$2.1 \mathrm{GHz}$ & $-18.813 \mathrm{~dB}$ & $-1.319 \mathrm{~dB}$ & 1.259 & 13.196 & $30 \mathrm{MHz}$ & - \\
\hline
\end{tabular}

Keep in mind that the value of good Return Loss as if its value is $<-10 \mathrm{~dB}$ or VSWR value $<2$. So the lower the number, the better the performance of an antenna. Based on the Table 4.6, the resonant frequency of $1.8 \mathrm{GHz}$ generated a good amount of Return Loss value of $-18.257 \mathrm{~dB}$ and VSWR value of 1.278 even there is a slight decrease from simulation results. Different results showed by working frequency of $2.1 \mathrm{GHz}$, the antenna generated the frequency worse than the simulation even value of Return Loss and VSWR are not qualified for the specifications. Value from the measurement is lower or even worse from the simulation probably because of common errors occured when the measurement is being done.

Viewed from any parameters, the value of Return Loss and VSWR that has been resulted from the antenna that have been measured, there are only significant problems for measurement results of working frequency $2.1 \mathrm{GHz}$ that are not in accordance with results that have been previously simulated. For resulting bandwidth, the antenna generate very narrow bandwidth both in the measurements results as well as simulation results for working frequency of $1.8 \mathrm{GHz}$. Nevertheless, the overall result is satisfying for working frequency of $1.8 \mathrm{GHz}$ and met the desired specification.

\subsection{Discussion of Radiation Pattern Antenna Parameters}

Based on the plot of the H-co radiation pattern in Figure 8, the measured antenna shows radiation pattern plot is having one main lobe and back lobe radiating wider than the main one which is caused by the radiation feed line. Thus, the radiaton pattern characteristics of the measured antenna can be said pretty much identical to simulation results. This means that the antenna is in accordance with its simulation design results. As in the measurement of $\mathrm{H}-\mathrm{co}$, the radiation pattern plot of E-co shows a plot that is basically similar with the simulated one which has wider with the hints of back lobe looks not so visible on measurement result. Nevertheless, the measurement result of the radiation pattern has graph results look close to the simulation result. 

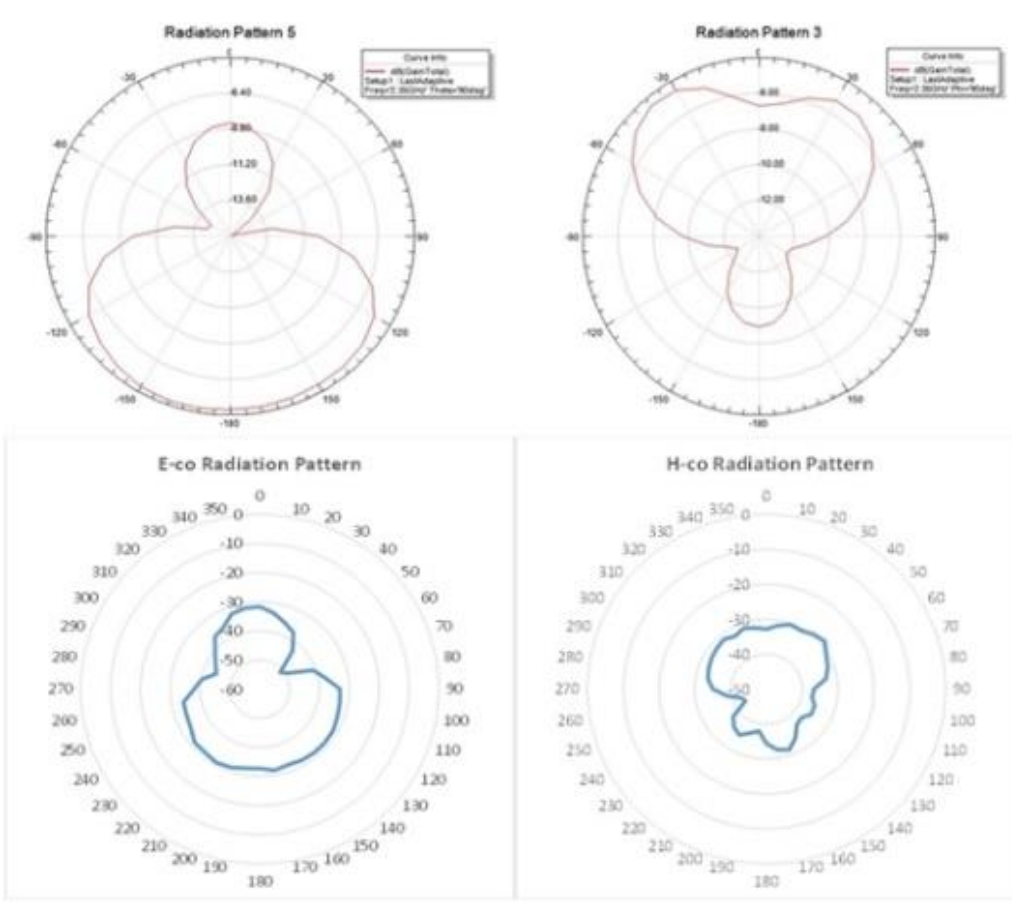

Figure 8. Comparisons of radiation pattern results (top: simulation result, bottom: measurement result)

\section{CONCLUSION}

After going through the process of designing the antenna and measure the fabricated antenna, several conclusions with some suggestions and ideas for further research which are drawn in the following: 1) Rectangular slotted circular ring microstrip patch antenna with aperture coupled feeding technique has been successfully designed with value of Return Loss value $-22.3683 \mathrm{~dB},-18,8133 \mathrm{~dB},-24.3451 \mathrm{~dB}$ and VSWR value $1.1648,1.259,1.1291$ respectively on working frequency of $1.8 \mathrm{GHz}, 2.1 \mathrm{GHz}, 2.72 \mathrm{GHz}$ with geometry parameters described as this, length and width of substrate are $130 \mathrm{~mm}$, length and width of ground plane are $130 \mathrm{~mm}$, feedline width is $2.9921 \mathrm{~mm}$, feedline length is $27.5484 \mathrm{~mm}$, inner radius of patch is $26.0848 \mathrm{~mm}$, outer radius of patch is $52.1696 \mathrm{~mm}$, length of aperture slot is $27 \mathrm{~mm}$, width of aperture slot is $2.7 \mathrm{~mm}$, length of stub is 5.8595 , length of side rectangular slots are $60 \mathrm{~mm}$, width of side rectangular slots are $7 \mathrm{~mm}$, length of upper rectangular slot is 2 and width of upper rectangular slot is $27.8 \mathrm{~mm}$. Meanwhile, the measurement results of fabricated antenna show the frequency produced by the antenna is $1.8 \mathrm{GHz}$ with value of Return Loss and VSWR -18.257 dB and 1.278 in a reference value of VSWR $<2$ and Return Loss < $-10 \mathrm{~dB}$; 2) The aperture coupled feeding technique could overcome the randomly generated working frequency on circular ring microstrip patch single element antenna; 3) The aperture coupled feeding technique could not overcome wider bandwidth on circular ring microstrip patch single element antenna; 4) The rectangular slots loading on the patch successfully generates multi resonant working frequency in accordance with desired specifications.

\section{REFERENCES}

[1] Fawwaz T. Ulaby. Fundamental of Applied Electromagnetics. Boston: Prentice Hall. 2001

[2] A. Ittipiboon, Inder Bhahl, P. Bhartia, R. Garg. "Microstrip Antenna Design Handbook". Boston: Artech House. 2000.

[3] Menteri Komunikasi Dan Informatika Republik Indonesia. 27/2015. Persyaratan Teknis Alat Dan/Atau Perangkat Telekomunikasi Berbasis Standar Teknologi Long Term Evolution. Jakarta: 2005.

[4] Indra Surjati, Yuli Kurnia Ningsih, Syah Alam. "Compact Fractal Patch Microstrip Antenna Fed by Coplanar Waveguide for Long Term Evolution Communications". 4th International Conference on Electrical Engineering, Computer Science and Informatics. Yogyakarta. 2017.

[5] Yulianto La Elo, Fitri Yuli Zulkifli, Eko Tjipto Rahardjo. "Design of Wideband Microstrip Antenna with Parasitic Element for 4G/LTE Application". 15th International Conference on Quality in Research: International Symposium on Electrical and Computer Engineering. Nusa Dua. 2017. 
[6] Zakaria Er-reguig, Hassan Ammor. "A Miniature BroadBand Microstrip Antenna for LTE, Wi-Fi and WiMAX Applications" International Journal of Electrical and Computer Engineering (IJECE), vol. 8, no. 6, pp. 5238-5244, December 2018.

[7] David M. Pozar. "A Review of Aperture Coupled Microstrip Antennas: History, Operation, Development and Application". Massachusetts. 1996.

[8] Neng-Wu Liu, Lei Zhu, Wai-Wa Choi, Xiao Zhang. A Low-Profile Aperture-Coupled Microstrip Antenna with Enhanced Bandwidth under Dual-Resonance. IEEE Transactions on Antennas and Propagation. 2017; 65(3z): 1055-062.

[9] Budhadeb Maity. "Design of Dual band L-Slot Microstrip Patch Antenna for Wireless Communication". International Conference on Computer Communication and Informatics. Coimbatore. 2017.

[10] Tushar Agale, M. M. Khanapurkar. "A Review on Design Approach for Performance Enhancement Techniques of Microstrip Patch Antenna". 3rd International Conference on Advances in Electrical, Electronics, Information, Communication and Bio-Informatics. Chennai. 2017.

[11] Vibha Raj Nag, Mrinal Sarvagya. "Review Paper on Different Dual Band Printed Slot Antenna for 5G Wireless Communication" International Journal of Electrical and Computer Engineering (IJECE), vol. 7, no. 3, pp. 105110, December 2018.

[12] Abil Fathir Majid, Yulisdin Mukhlis. "Design of Circular Ring Microstrip Patch Antenna with an H-Shaped Sloton the Ground Plane for WiMAX”. 2nd International Conference on Informatics and Computing. Jayapura. 2017.

[13] Teguh Firmansyah, Supriyanto Praptodiyono, Herudin, Didik Aribowo, Syah Alam, Dian Widi Astuti, Muchamad Yunus. "Bandwidth Enhancement and Miniaturization of Circular-Shaped Microstrip Based on Beleved Half-Cut Structure for MIMO 2x2 Application" International Journal of Electrical and Computer Engineering (IJECE), vol. 9, no. 2, pp. 1110-1121, April 2019.

[14] A. H. Majeed, K. H. Sayidmarie. "Extended-Bandwidth Microstrip Circular Patch Antenna for Dual Band Applications" International Journal of Electrical and Computer Engineering (IJECE), vol. 8, no. 2, pp. 1056-1066, April 2018.

[15] W. Kin Lu, C.C. Huang, W.S. Chen. "Printed Ring Slot Antenna for Circular Polarization". IEEE Transactions on Antennas and Propagation. 2002; 50(1): 75-77.

[16] Debajyoti Chatterjee, Anjan Kumar Kundu. "Performance Analysis and Comparative Study of Microstrip Patch Antenna using Aperture Coupled and Proximity Coupled Feeding Methodology". International Conference on Computer, Communication, and Signal Processing. Chennai. 2017.

[17] S. Sibi Chakravarthy, N. Sarveshwaran, S. Sriharini, M. Shanmugapriya. "Comparative Study on Different Feeding Techniques of Rectangular Patch Antenna". 13th International Conference on Wireless and Optical Communications Networks. Hyderabad. 2016.

[18] Adel Bedair. "Design and Development of High Gain Wideband Microstrip Antenna and DGS Filters Using Numerical Experimentation Approach”. PhD Thesis. Otto-von-Guericke-Universität Magdeburg; 2005.

[19] Swarup Das, Debasis Mitra, Sekhar Ranjan Bhadra Chaudhuri. "I-Shaped Fractal Slot Loaded Multiband Microstrip Patch Antenna for Wireless Applications". International Conference on Computer, Electrical \& Communication Engineering. Kolkata. 2016.

[20] Xiaosheng Guo, Weiwei Liao, Qingfeng Zhang, Yifan Chen. "A Dual-Band Embedded Inverted T-Slot Circular Microstrip Patch Antenna". 5th Asia-Pacific Conference on Antennas and Propagation.Kaohsiung. 2016. 